\title{
Risk taking sexual behaviors among young adults - findings from a cross sectional population based survey in Barbados
}

\author{
Alok Kumar*, Nicole Drakes, Shawna Crichlow, Keagan \\ Mohammed and Jacqueline Wiltshire \\ National HIVIAIDS Commission Barbados, The University of the West Indies (Cave Hill), \\ Barbados; The Ladymeade Reference Unit, Ministry of Health, Barbados
}

\section{Abstract}

Background: The National Strategic Plan for HIV Prevention and Control 2014-2018 recognized the need for the utilization of research findings to guide the development of HIV policies, programs and interventions for the general population and key population groups and to inform the allocation of government resources to the areas of greatest impact and need. To this end, a Knowledge, Attitudes, Beliefs and Sexual Practices Survey (KABP) was conducted among adults' ages 15 to 49 years.

Objectives: To identify the sexual behaviors among adolescents and young adults that exposed them to the risks of HIVISTIs and to identify factors that may have to be addressed, in order to achieve further reduction in the spread of HIV in this population.

Methods: This is a population based cross-sectional survey undertaken in 2016. Sample was taken from among persons' ages $15-49$ years using a multistage sampling methodology. The survey questionnaire was developed from Family Health International's guidelines for repeated behavioral surveys in populations at risk of HIV. It was interviewer-administered and consisted of ninety-nine (99) closed-ended questions. The topics covered by the survey included sexual history; use of and access to condoms; and HIV testing. Participants were asked about their sexual behaviors over the last 12 months, and about their experience with their most recent partner.

Results: Overall, $87.8 \%$ described themselves as heterosexual, $1.2 \%$ as bisexual and $0.5 \%$ as homosexual. By the age 16,17 nd 19 years $25 \%, 50 \%$ and $75 \%$ of respondents have had sex respectively. Among the 763 respondents reporting vaginal or anal sex over the past 12 months, 80.6 and $19.4 \%$ had a single and multiple sex partner respectively. Also, $94.4 \%, 13.3 \%$ and $1.6 \%$ reported to have regular, non-regular and commercial sex partners respectively. Overall, $54.6 \%$ used condom at the last sex, the corresponding figure for the regular and non-regular partners were $41.2 \% 80.8 \%$ respectively. Only $40.9 \%$ reported to have had a HIV test done over the past 12 months and of those who did not, $42.8 \%$ had never been tested for HIV.

Conclusion: Inconsistent and infrequent condom use and low HIV testing especially among the adolescents and younger adults, in the setting of young ages at sexual debut and multiple sexual partners. Findings form this study strongly recommends for a much greater effort from the public health at promoting condom use and HIV testing especially targeting the younger persons who risk their own protection and that of their partners.

\section{More Information}

*Address for Correspondence: Alok Kumar, MD., Professor, Faculty of Medical Sciences, The Queen Elizabeth Hospital, Martindales Road, Bridgetown St. Michael, Barbados,

Tel: 1(246)4366450;

Email: alok.kumar@cavehill.uwi.edu; alokkumar.uwichill@gmail.com

Submitted: 15 April 2020

Approved: 22 May 2020

Published: 25 May 2020

How to cite this article: Kumar A, Drakes N, Crichlow S, Mohammed K, Wiltshire J. Risk taking sexual behaviors among young adultsfindings from a cross sectional population based survey in Barbados. Int J Clin Virol. 2020; 4: 047-055.

\section{DOI: 10.29328/journal.ijcv.1001015}

Copyright: @ 2020 Kumar A, et al. This is an open access article distributed under the Creative Commons Attribution License, which permits unrestricted use, distribution, and reproduction in any medium, provided the original work is properly cited.

Keywords: Human Immunodeficiency virus; Risk behavior; Young adults; Condom use; Human Immunodeficiency virus test; Caribbean

Check for updates

OPEN ACCESS

\section{Introduction}

In recent years, many of the countries that were most affected by HIV have registered a reduction in the incidence of HIV [1-6]. Although, this success has been largely attributed to the universal access to HIV treatment and treatment as prevention programs, many studies in these countries have shown that the behavior change among young adults have contributed significantly to the overall reduction in the incidence of HIV [1-4]. HIV awareness could lead to community discourses and social interactions that can influence commonsense assumptions and meanings linked to HIV prevention. 
In recent years, many studies and recommendations have highlighted the importance of focusing on young people and their risky sexual behaviors, to achieve further reduction in new cases of HIV infection $[5,7,8]$. However, in too many cases, young people continue to exhibit risk taking behaviors which may partly be due to insufficient information and understanding about HIV and this has been evident in reports from the Caribbean and elsewhere [9-12].

Barbados had a well-planned HIV program since very early in the epidemic which was backed by a strong political commitment with universal free access to treatment and prevention since late 1990's. Since the peaking of the HIV epidemics during 1999 and 2000, Barbados has seen a gradual downward trend in the rate of new HIV infections and a significant reduction in the number of AIDS-related hospitalization and deaths [13-15]. However, new infections continue to occur especially among the young adults (access to the surveillance data from the ministry of health). The government of Barbados is committed to meeting the targets of "Getting to Zero" initiative. Against this background we conducted a survey on HIV knowledge, attitudes, beliefs and sexual practices among adults with ages between 15 and 49 in Barbados. The major objectives of this survey were to assess the risk-taking behaviors of persons between the ages of 1549 that may be predisposing them to HIV and to identify their risk reduction practices. In this report, we present the findings from this survey on the sexual behaviors of the young adults that may predispose them to HIV/STI and to identify their risk reduction practices.

\section{Materials and methods}

\section{Study design}

This was a population based cross-sectional survey conducted during late 2015 and early 2016. A sample of this population was taken from among persons' ages 15 - 49 years, using preliminary data from the 2010 census conducted by the Barbados Statistical Service.

Inclusion Criteria: (i). Persons must range in age from 15 to 49 years; (ii). Persons must have been living in Barbados for at least 6 months; if they are not a citizen of Barbados; (iii). Persons must be capable of giving informed consent or have an acceptable party to give informed consent on their behalf.

\section{Sampling methods}

The sample sizes were determined using the prevalence of two key questions from the 2009 and 2010 KABP Surveys. These key questions were: (1) Have you had sexual intercourse in the last 12 months? (2) Was a condom used the last time you had sexual intercourse? The sample size was calculated using a margin of error ranging from $2.5 \%$ to $5 \%$ and a type 1 error rate of $5 \%$. A power of 0.5 was used in STATA to calculate these sample sizes since it was a prevalence survey instead of a group comparison. This calculation was possible because obtaining a given level of precision in a survey was less demanding than showing a difference between groups (for which $80 \%$ power or greater is always used). A sample size of 1068 with a margin of error of 3 was proposed.

The survey utilized a multistage sampling methodology:

Stage 1 - the selection of a $10 \%$ random sample of enumeration districts (EDs) or 60 EDs

Stage 2 - the selection of twenty (20) households within each of the sixty (60) EDs

Stage 3 - the random selection of a prospective respondent from each pre-selected household by interviewers using the Kish method.

\section{Survey structure and delivery}

The survey questionnaire was developed from Family Health International's “Guidelines for Repeated Behavioral Surveys in Populations at Risk of HIV: Behavioral surveillance surveys [16]. It was interviewer-administered and consisted of ninety-nine closed-ended questions. The topics covered by the survey included sexual history; use of and access to condoms; and HIV testing. Participants were asked about their sexual behaviors over the last 12 months, and about their experience with their most recent partner. In order to address issues with survey design, the instrument was pretested among a sample of respondents similar to the study population.

Respondents were asked questions about their sexual practices and history specifically:(1) Whether they ever had sex (i.e. oral, vaginal or anal); (2) The age at first sex;(3) Amount and type of sex partners they had within the past 12 months; (4) Condom use practices; (5) Whether they ever had sex under the influence of drugs or mind-altering substances; and (6) Incidence of men having sex with other men

The survey looked at the magnitude of men having sex with men and sought to capture data on: (1) whether male respondents had ever had sex with other men; (2) whether male respondents had had sex with other males in the past 12 months; (3) the number of male sex partners; and (4) whether a condom was used at last sexual activity.

The survey specifically examined the issue of condom use in four areas of respondents' sexual history in relation to three partner categories - regular, non-regular and commercial sex partners: (1) consistency of condom use; (2) decision to use condoms; (3) reasons for condom use; and (4) condom availability and access.

On HIV testing, respondents were asked (1) if they knew where they could get an HIV test, (2) to identify testing locations/venues, (3) if they had ever had an HIV test, and (4) if they had found out the results of the HIV test.

Due to the sensitive nature of the study, several measures 
were instituted to safeguard respondent confidentiality including the non-recording of personal identifiers; obtaining informed consent assent from respondents ages 18 and older, and those under the age of 18 respectively; all members of the research team were trained in research ethics, interview practices, use of the Kish method and Enumeration District mapping; interviewers were assigned an ED with which they were unfamiliar; and interviews were conducted in private. The Kish Selection Method is a method for selecting members within a household to be interviewed. It uses a pre-assigned table of random numbers to find the person to be interviewed.

\section{Ethical approval}

Ethical approval was obtained from the Ministry of HealthUniversity of the West Indies Institutional Review Board before conducting the survey.

\section{Outcome definitions}

Intergenerational sex, defined by the Joint United Nations Program on HIV/AIDS (UNAIDS) as sexual intercourse between two persons where one partner is ten (10) years or older than the other partner, has been identified particularly in the case of women as one of the factors contributing to HIV transmission.

Regular partner includes a spouse or live-in sexual partner, or a person with whom you are involved in a committed relationship.

Commercial partner refers to a person with whom you had sex in exchange for money or gifts.

Non-regular partner includes sexual partners to whom you are not married and have never lived with or a person that you are not involved in a committed relationship.

\section{Data analysis and statistical methods}

The entire data processing phase of the survey entailed the use of a system of double data-entry to minimize inconsistencies in the data set. Statistical analysis was completed using the Statistical Package for the Social Sciences (SPSS) version 21. Analyses were weighted to account for the sampling design and to match the age-sex distribution of the Barbadian population according to the 2010 Barbados Population and Housing Census. All proportions had 95\% Confidence Interval calculated with correction for continuity. Odds Ratio was calculated for categorical variables. $\mathrm{P}<0.05$ was taken as statistically significant.

\section{Results}

\section{Sociodemographic characteristics of respondents}

The Survey yielded 1, 016 completed questionnaires from the sample size of 1068 , representing a $95.1 \%(95 \% \mathrm{CI}=$ $93.6 \%, 96.3 \%$ ) response rate. Table 1 shows the selected sociodemographic characteristics of the respondents. When asked about their sexual orientation, 892 (87.8\%; 95\% CI = 85.6\%,

\begin{tabular}{|c|c|c|}
\hline Characteristic & Sample $n$ & $\begin{array}{l}\text { Sample Proportion } \\
\text { (95\% Confidence Interval) }\end{array}$ \\
\hline \multicolumn{3}{|c|}{ Age at last birthday $(n=1016)$} \\
\hline $15-19$ & 124 & $12.2(10.3,14.4)$ \\
\hline $20-24$ & 157 & $15.4(13.3,17.8)$ \\
\hline $25-29$ & 131 & $12.9(10.9,15.1)$ \\
\hline $30-34$ & 129 & $12.7(10.7,14.9)$ \\
\hline $35-39$ & 147 & $14.5(12.4,16.8)$ \\
\hline $40-44$ & 162 & $15.9(13.8,18.4)$ \\
\hline $45-49$ & 166 & $16.3(14.1,18.8)$ \\
\hline \multicolumn{3}{|c|}{$\operatorname{Sex}(n=1016)$} \\
\hline Male & 460 & $45.3(42.2,48.4)$ \\
\hline Female & 556 & $54.7(51.6,57.8)$ \\
\hline \multicolumn{3}{|c|}{ Race $(n=1003)$} \\
\hline Black (Afro-Caribbean) & 947 & $94.4(92.8,95.7)$ \\
\hline Others & 56 & $5.6(4.3,7.2)$ \\
\hline \multicolumn{3}{|c|}{ Religion $(n=1009)$} \\
\hline Christian Religions & 717 & $71.1(68.1,73.8)$ \\
\hline Non-Christian Religions & 31 & $3.1(2.1,4.4)$ \\
\hline No Religion & 261 & $25.9(23.2,28.7)$ \\
\hline \multicolumn{3}{|c|}{ Education level $(n=1014)$} \\
\hline Primary & 27 & $2.7(1.8,3.9)$ \\
\hline Secondary & 471 & $46.4(43.3,49.6)$ \\
\hline Post-Secondary & 111 & $10.9(9.1,13.1)$ \\
\hline Tertiary & 405 & $39.9(36.9,43.0)$ \\
\hline \multicolumn{3}{|c|}{ Occupational Status $(n=1060)$} \\
\hline Student & 167 & $16.5(14.3,18.9)$ \\
\hline Employed & 721 & $71.2(68.2,73.9)$ \\
\hline Unemployed & 165 & $16.3(14.1,18.7)$ \\
\hline Other & 7 & $0.7(0.3,1.5)$ \\
\hline \multicolumn{3}{|c|}{ Marital status $(n=994)$} \\
\hline Married & 175 & $17.6(15.3,20.1)$ \\
\hline Single & 741 & $74.5(71.7,77.2)$ \\
\hline Others & 78 & $7.8(5.7 .0,9.6)$ \\
\hline
\end{tabular}

89.7\%) of respondents described themselves as heterosexual, whereas $12(1.2 \%$; $95 \% \mathrm{CI}=0.6 \%, 2.1 \%)$ as bisexual and 5 $(0.5 \% ; 95 \% \mathrm{CI}=0.2 \%, 1.2 \%)$ as homosexual. In response to the questions on whether they have ever had oral, vaginal or anal sex, 899/1014(88.7\%; 95\% CI $=86.5 \%, 90.5 \%)$ reported as having had vaginal sex, $574 / 1014(56.62 \% ; 95 \% \mathrm{CI}=53.5 \%$, $59.7 \%)$ reported as having had oral sex and 59/1003(5.9\%; $95 \% \mathrm{CI}=4.5 \%, 7.6 \%)$ reported to have had anal sex. Overall, $899 / 1016$ (88.5\%; 95\% CI = 86.3\%, 90.3\%) reported to have had vaginal and/or anal sex.

\section{Age at sexual debut and the age of sexual partner at debut}

Figure 1 presents the data on age at first sex, based on life table analysis, in this group of participants aged 15 to 24 at the time of interview. Using the censored life table analysis, $25 \%$ of participants have had sex by 16 years of age (lower quartile), $50 \%$ have had sex by 17 years of age (median), and $75 \%$ of participants have had sex by 19 years of age (upper quartile). The largest proportion of persons had first oral (37.5\%) and vaginal (64.3\%) sex between the ages of 15 and 19 , and anal sex (38.3\%) between the ages of 20 and 24 . The survey also examined the issue of intergenerational sex. The first sexual partner for $37 / 844$ (4.4\%; $95 \% \mathrm{CI}=3.1 \%, 6.0 \%$ ) 


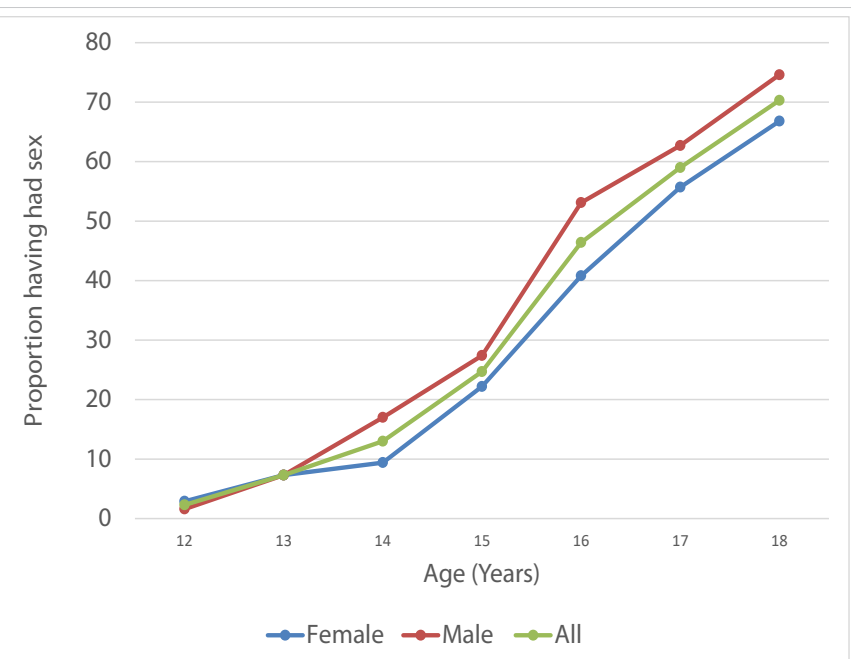

Figure 1: Age at first sex among 281 KABP participants (147 female, 134 male) aged 15 to 24 .

of the respondents, was an intergenerational (10 or more years older or younger than himself or herself) sex partner. However, additional 86/844 (10.2\%; 95\% CI = 8.3\%, 12.5\%) reported that the partner was older or younger but they were not sure of their age.

\section{Analysis of sexual partner}

Of the 899 respondents who reported having had vaginal and/or anal sex, 749 (83.3\%; 95\% CI $=80.7 \%, 85.7 \%$ ) indicated that they had vaginal and/or anal sex during the last year. Selected aspects of the sexual experiences of these 749 respondents who reported to be sexually active over the past year is shown in table 2. Further analysis of the sexual experiences among various age groups of the respondents who reported to have had vaginal and/or anal sex and who were sexually active over the past 12 months (749 respondents) was also undertaken. Of the 187 of those under 25 years old, 124 (66.3\%; 95\% CI = 59.0\%, 72.9\%) reported single partners and 62 (33.2\%; 95\% CI $=26.6 \%, 40.5 \%)$ reported multiple partners with 1 non-responder. Whereas, of the 562 respondents who were 25 or older, 479 (85.2\%; 95\% CI = $82.0 \%, 88.0 \%$ ) reported a single partner and 83 (14.8\%; 95\% $\mathrm{CI}=12.0 \%, 18.0 \%)$ reported multiple partners over the past 12 months. These differences were statistically significant (Odds Ratio $=2.9 ; 95 \% \mathrm{CI}=2.0,4.45 ; p<.0001$ ).

For the 498 respondents with highest level of education being up to the secondary level, $173(34.7 \%$; $95 \% \mathrm{CI}=30.6 \%$, $39.1 \%$ ) reported to have multiple partners over the past 1 year while for those 516 respondents with post-secondary and tertiary level education $132(25.6 \% ; 95 \% \mathrm{CI}=21.9,29.6)$ reported multiple partners (Odds Ratio 1.55; $95 \% \mathrm{CI}=1.18$, 2.03; $\mathrm{P}=0.0015)$. Among the respondents who reported multiple partners, $112 / 721(15.5 \%$; $95 \% \mathrm{CI}=13.1,18.4)$ were employed, $52 / 165$ (31.5\%; 95\% CI $=24.6,39.3)$ were unemployed and $43 / 167$ (25.5\%; 95\% CI = 19.4, 33.2\%) were students. The difference in the proportions of having multiple partners among the three groups was statistically significant $(p<0.0001)$.

Further analysis, of the type of partners versus multiplicity of partners showed that 45/707 (6.4\%; $95 \mathrm{CI}=4.7 \%$, 8.5\%) respondents with regular partners reported having had multiple regular partners compared with $41 / 100$ (41\%; $95 \mathrm{CI}$ $=31.4 \%, 51.3 \%$ ) respondents with non-regular partners who reported having multiple non-regular partners. The difference in the likelihood of having multiplicity of non-regular partners as compared to multiplicity of regular partner was statistically significant $(\mathrm{OR}=0.093 ; 95 \% \mathrm{CI}=0.056,0.154 ; p<0.0001)$. Analyzing the 462 male respondents, 408 (88.3\%) reported to have had sex. Of these 408 sexually active men, $7(1.8 \%)$ reported having a male sexual partners.

Table 2: Sexual experiences of the 749 respondents who reported to have had vaginal and/or anal sex over the past 12 months.

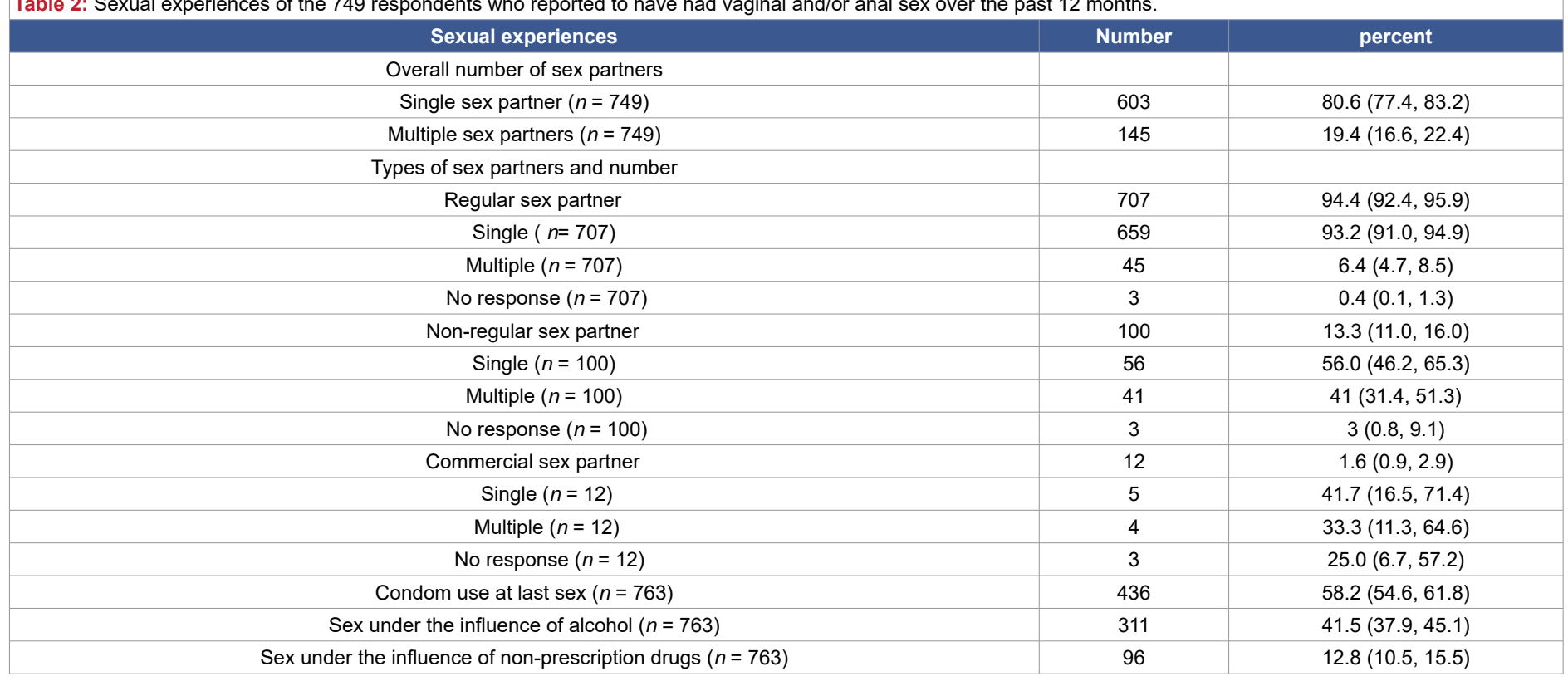




\section{Condom use}

Overall, 890/938 (94.9\%; 96\% CI $=93.2 \%, 96.2 \%)$ stated that they were able to access a male condom and 407/886 (45.9\%; $95 \% \mathrm{CI}=42.6 \%, 49.3 \%)$ stated that there were able to access a female condom. When analyzing condom use at last sexual activity, a proxy measure was used to measure consistent condom use. The survey revealed that, overall, 389/834 (46.6\%; 95\% CI $=43.2 \%, 50.1 \%$ ) used condoms at last sexual activity. Looking at the condom usage among various age groups, 78/247 (31.6\%; 95\% CI = 25.9\%, 37.8\%) of under 25 years respondents and 311/587 (53.0\%; 95\% $\mathrm{CI}=48.8 \%, 57.1 \%)$ of 25 years and older respondents used condoms at their last sexual activity respectively. This difference in condom use among under 25 years and older respondents was statistically significant (OR $=0.41 ; 95 \% \mathrm{CI}$ $=0.30,0.56 ; \mathrm{P}<0.0001)$. Condom use with different types of partners revealed that $331 / 807(41.0 \% ; 95 \% \mathrm{CI}=37.6 \%$, $44.5 \%$ ) and $97 / 120$ (80.8\%; $95 \% \mathrm{CI}=72.4 \%, 87.2 \%$ ) of respondents used condoms the last time they had sex with their regular and non-regular partners respectively (Table 3). This difference was statistically significant $(\mathrm{OR}=0.16 ; 95 \% \mathrm{CI}$ $=0.10,0.25 ; p<0.0001$ ).

\section{HIV testing}

Overall, 414/1011 (40.9\%; 95\% CI = 37.9\%, 44.1\%) had an HIV test within the last 12 months (Table 4). Of these persons, $386 / 396$ (97.5\%; 95\% CI = 95.2\%, 98.7\%) found out their test results. Analysis of HIV testing over the past 12 months and sociodemographic characteristics of the respondents reveled the following findings. Overall, $69 / 289$ (23.9\%; 95\% CI = $19.2 \%, 29.3 \%$ ) of under 25 years respondents and $345 / 722$ (47.8\%; 44.1\%, 51.5\%) had an HIV test in the past 12 months $(\mathrm{OR}=0.34 ; 95 \% \mathrm{CI}=0.25,0.47 ; p<0.0001)$. Among the respondents the highest level of education was either at the primary level or the secondary level, $28.5 \%$ (95\% CI $=24.6 \%$, $32.7 \%$ ) had an HIV test done while the corresponding figure

Table 3: Condom use with regular and non-regular sex partners.

\begin{tabular}{|c|c|c|c|c|}
\hline \multirow[b]{2}{*}{ Condom use at last sex } & \multicolumn{2}{|c|}{ Regular Partners } & \multicolumn{2}{|c|}{ Non-regular partners } \\
\hline & $n=807$ & Percentage & $n=120$ & Percentage \\
\hline Yes & 331 & $41.2(37.6,44.5)$ & 97 & $80.8(72.4,87.2)$ \\
\hline No & 471 & $58.5(54.9,61.8)$ & 22 & $18.3(12.1,26.7)$ \\
\hline Don't know/Don't remember & 5 & $0.6(0.2,1.5)$ & 1 & $0.8(0.0,5.2)$ \\
\hline Reasons for not using condom & $n=440$ & percentage & $n=20$ & Percentage \\
\hline Didn't think it was necessary & 311 & $70.2(65.7,74.4)$ & 4 & $20.0(6.6,44.3)$ \\
\hline Don't like them & 32 & $7.2(5.1,10.1)$ & 5 & $25.0(9.6,49.4)$ \\
\hline Used other contraceptive & 30 & $6.8(4.7,9.6)$ & 0 & $0.0(--)$ \\
\hline Allergic to latex & 15 & $3.4(2.0,5.6)$ & 2 & $10.0(1.7,33.1)$ \\
\hline Didn't think of it & 15 & $3.4(2.0,5.6)$ & 3 & $15.0(4.0,38.9)$ \\
\hline Not available & 11 & $2.5(1.3,4.5)$ & 3 & $15.0(4.0,38.9)$ \\
\hline Partner objected & 4 & $0.9(0.3,2.4)$ & 0 & $0.0(--)$ \\
\hline Other & 20 & $4.5(2.8,7.0)$ & 3 & $15.0(4.0,38.9)$ \\
\hline Don't know/Don't remember & 2 & $0.4(0.3,0.7)$ & 0 & $0.0(--)$ \\
\hline Condom use in past 12 months & $n=696$ & Percentage & $n=114$ & Percentage \\
\hline Every time & 182 & $26.1(22.9,29.6)$ & 71 & $62.3(52.7,71.0)$ \\
\hline Almost every time & 75 & $10.8(8.6,13.4)$ & $16(14.0$ & $14.0(8.5,22.1)$ \\
\hline Sometimes & 104 & $14.9(12.4,17.9)$ & 13 & $11.4(6.4 .19 .0)$ \\
\hline Never & 333 & $47.8(44.1,51.6)$ & 14 & $12.3(7.1,20.1)$ \\
\hline Don't know/Don't remember & 2 & $0.3(0.1,1.2)$ & 0 & $0(--)$ \\
\hline
\end{tabular}

Table 4: The HIV testing patterns and the respondent's select sociodemographic characteristics among adults (15 to 45 years) in Barbados.

\begin{tabular}{|c|c|c|c|}
\hline Sociodemographic Characteristics & $n(\%)$ & 95\% Confidence Interval & ODDS RATIO; $95 \%$ CI ( $p$ values) \\
\hline \multicolumn{4}{|l|}{ Age group } \\
\hline $15-<25$ Years & $69(23.9)$ & $19.2,29.3$ & \\
\hline $25-45$ Years & $345(47.8)$ & $44.1,51.5$ & $2.92 ; 2.14,3.97(<0.0001)$ \\
\hline \multicolumn{4}{|l|}{ Highest level of Education } \\
\hline Primary/Secondary level & $142(28.5)$ & $24.6,32.7$ & \\
\hline Post-Secondary/Tertiary level & $266(51.6)$ & $47.2,55.9$ & $2.67 ; 2.01,3.46(<0.0001)$ \\
\hline \multicolumn{4}{|l|}{ Employment status } \\
\hline Employed & $371(51.5)$ & $47.7,55.2$ & \\
\hline Unemployed & $40(24.2)$ & $18.1,31.6$ & $0.30 ; 0.21,0.44(<0.0001)$ \\
\hline \multicolumn{4}{|l|}{ Marital status } \\
\hline Married & $42(24.0)$ & $18.0,31.1$ & \\
\hline Single & $420(56.7)$ & $53.0,60.3$ & $4.14 ; 2.84,6.03(<0.0001)$ \\
\hline
\end{tabular}


for those with the highest level of education being at the post-secondary or tertiary level was $51.6 \%$ (95\% CI $=47.2 \%$, $55.9 \%$ ) Exploring the reason for HIV testing revealed that the majority, 243/401 (60.6\%; 95\% CI $=55.6 \%, 65.4 \%)$ had their test done as part of their routing health checks. Conversely, of those who did not receive a test in the last 12 months, 248/580 (42.8\%; 95\% CI $=38.7 \%, 46.9 \%$ ) had never been tested for HIV.

\section{Sexually transmitted infections}

Overall, $48.0 \%$ and $45.5 \%$ of respondents were able identify a genital discharge as an STI symptom in women and men respectively. In terms of action taken to address STI symptoms, most respondents told their sexual partner about the discharge $(75.7 \%)$ or sought advice/medicine from a private clinic or hospital (72.5\%).

\section{Discussion}

In Barbados, according to latest Ministry of Health data, HIV prevalence among the adult population aged 15 to 49 was estimated at $0.86 \%$ in 2013 and the HIV prevalence was highest in the $30-39(1.18 \%)$ and $40-49$ (1.34\%) age groups [17] and over $40 \%$ of all new cases were diagnosed in persons younger than 35 years of age [18]. The majority of the new cases of HIV in this country is diagnosed when the individuals are symptomatic [18]. Given the fact that usual latency in the clinical presentation of HIV infection is 10 to 15 years, most of these cases are most likely infected when they were 15 to 25 years old. The drivers of the epidemic in this population are thought to be complex and multi-layered and include early age of first sexual activity, gender-based violence, cultural norms such as multiple concurrent partnerships and sex for money or favors, as well as the social exclusion of certain groups based on sexuality or sexual orientation. ${ }^{17,19-21}$ Studies from the Caribbean and those from the sub-Saharan Africa have shown that risk taking behaviors among the young adults, remain at the center of continuing spread of HIV [9-12].

Findings from this population based survey provides a better understanding of the risk taking behaviors as well as the risk reduction practices among the young adults, especially the under 25 years population, in this country as possible determinants of the dynamics of current HIV epidemics and the driving force behind the continued occurrence of new cases in this population, which is essential for implementing additional strategy to achieve further reduction in HIV prevalence in this country.

Young age at sexual debut was an important finding in this survey with nearly half of the respondents reporting to have had sex before 16 years of age. Similar findings were reported from an earlier survey of the secondary school children in this country. ${ }^{21,22}$ This is a recurring finding in similar surveys from many of the other Caribbean countries as well $[11,12]$. Most countries form sub-Saharan Africa with higher prevalence of
HIV have reported younger age at sexual debut compared to age at sexual debut in countries with lower HIV prevalence [23-25]. These findings have implications for prevention of HIV and other STI's, given the fact that in this country, condoms are sold exclusively at the grocery stores and gas stations and students seldom if ever visit these places. There is free condom distribution in this country in various settings from time to time, but none of them target this under-18 population. Much of the young adults under 25 years of age who are at university and colleges also fall in the same group as the adolescents. In fact, the idea of adolescents buying condoms or even having access to condoms in of itself would be socially unacceptable. Therefore, much of this sexually active, at risk population cannot access condoms for protection against the HIV and other STI's as condoms have not been made available in places frequented by youngsters.

Nearly a fifth of those sexually active over the past 12 months, reported having had multiple sexual partners. Even more worrying, respondents under 25 years were significantly more likely to report multiple sexual partners. Also, of concern was the fact that a sixth of the respondents reported having one or more non-regular partners. Of additional concern was the fact that nearly a fifteenth of those who reported regular partners, had multiple regular partners and over two-fifths of those reporting non-regular partner, had multiple nonregular partners. Once again, these figures are comparable to those reported from those reported in similar surveys from other Caribbean countries $[11,12]$. The concern with this sort of pattern of sexual practice, stems from the fact that usually people are more casual in self-protection from HIV/STI's when it comes to regular partners which is evident from the finding of a high percentage of respondents not using condoms or not using condoms consistently with their regular partners as they did not see the need of it with a regular partner. When these persons with regular partners have multiple other partners both regular and non-regular, as well as some with commercial sex partners, then they are putting their regular partners at a higher risk of HIV/STI's, compared to the situation where they had just a single regular partner. Also, persons often have multiple regular partners in succession with frequent change of regular partners as seen in previous studies in the same papulation [26,27]. Therefore, over the period of a sexually active life time a person with multiple nonregular and/or commercial sex partners could potentially put risk of STI's/HIV infection to their multiple regular partners without observing protective measures. These are reported to be highly risky behaviors for the transmission of HIV [28,29]. Individuals with multiple sex partners were also significantly less likely to have disclosed their HIV status [30] and could be a strong force for occurrence of new cases and the continuing epidemic in this population.

Another significant finding was that nearly half (44.2\%) of those who had sex during the last 12 months reported to be under the influence of non-prescription drug and/or alcohol 
and over a tenth were under the influence of both drug and alcohol during the last sexual encounter. Similar findings have been reported form the Republic of Trinidad and Tobago, another English speaking Caribbean country [11]. These are known to be risky behaviors for HIV/STI transmission [31,32]. Persons reporting sex under the influence of alcohol are also more likely to have multiple sexual partners [32]. Several studies have reported on the risk of sex under the influence of drugs and/or alcohol and the associated unlikelihood of condom use in HIV spread [31-33].

This survey also revealed that, overall, less than half of the respondents used condoms during their last sexual encounter. The condom use at last sexual activity was even worse with under 25 years respondents who reported a significantly lower percentage compared to older respondents. Similarly low usage of condoms $(<45 \%)$ have been reported from other Caribbean countries [11,12]. Condom was significantly more likely used with the non-regular partners than regular partner. Of note, use of condoms in over four-fifths of sexual encounters with non-regular partners is particularly high when compared to several other studies $[2,4,30]$. This may be explained by the higher risk perception in sexual intercourse with non-regular partners. This higher risk perception may be reflected in the fact that condom use, was respondent initiated, in over half the times when the sexual intercourse was with a non-regular partner, where as it was by mutual consent in nearly two-thirds of time while having sexual intercourse with regular partner.

Regular sex partners of participants with multiple partnerships were significantly less likely (less than half the times) to be protected by condoms than the non-regular partners. Similar observations have been made in other studies $[30,33]$. High condom usage during sex with nonregular partners may be the result of sustained and intense public education on the need for condom use for protection against HIV/STI's in this country over the 20 years. It is a protective behavior and continuing public education is necessary to encourage people to use condoms at every sexual encounter at least with non-regular partners.

HIV testing is done free of charge at any of the government run primary health care centers. However, less than half of the respondents have had a HIV test in the past 12 months. The figure was significantly lower for the respondents under 25 years of age, among whom the majority of the new HIV infection is diagnosed. Similar findings have been reported in surveys from other countries [34]. More concerning, of those who reported to have been not tested during the past 12 months, had never been tested for the HIV. This is an interesting finding as normally multiple sex partners and alcohol use during sex, both of which were reported in a significant proportion of our respondents, are associated with heightened perceived risk of HIV infection and therefore higher likelihood of voluntary HIV test uptake $[35,36]$. The findings that a large majority of young adults at risk of HIV never take an HIV test and are unaware of their HIV status poses a risk to their sex partners, especially the regular partners where the condom use is least likely. Previous studies using mathematical models have revealed that approximately $50 \%$ of new HIV infections are from HIVinfected persons who are unaware of their HIV status [37]. HIV testing provides an opportunity for people to find out their HIV status. Therefore, knowing one's HIV status may influence changes in personal behavior, which makes individuals more vulnerable to becoming infected or infecting others with HIV, thus helping to reduce the spread of HIV [38,39]. Knowing the status is central to many of the therapeutic interventions for prevention of HIV spread. Low HIV test uptake in this setting would make any of the common therapeutic interventions for HIV prevention difficult to implement and unsuccessful. Delayed HIV testing makes it more difficult to prevent the spread of the infection [40].

In conclusion, young age at sexual debut and multiple sexual partners is common. Men who have sex with men is not reported to the extent of being a significant contributor to the likely HIV spread in this population. Among sexually active persons less than 25 years, less than a third used condom at last sex and less than a fourth had an HIV test over the last year and these could be an important factor fueling the epidemics in this setting. Sex under the influence of alcohol and illicit drugs could be an important contributing factor in the risk for new HIV infection.

In light of the findings from this study, several programmatic recommendations could be made. More intensive and targeted condom programming is needed in light of the practice of inconsistent condom use. Measures to enhance ease of availability of condoms to vulnerable population such as the secondary school and college students may be very beneficial. Develop and implement targeted interventions inclusive of new messages for the most affected populations to encourage the practice of consistent condom use as a means of protecting themselves from contracting HIV and other STIs. However, the development of such interventions should be prefaced and directed by the determinants of condom use. More innovative campaigns or initiatives should be developed and implemented to promote HIV testing particularly among those who have never been tested. Once again, this campaign should include secondary school children and college students as target population.

\section{References}

1. Gregson S, Gonese E, Hallett TB, Taruberekera N, Hargrove JW, et al. HIV decline in Zimbabwe due to reductions in risky sex? Evidence from a comprehensive epidemiological review. Int J Epidemiol. 2010; 39, 1311-1323.

PubMed: https://www.ncbi.nlm.nih.gov/pubmed/20406793

2. Kembo J. Changes in sexual behaviour and practice and HIV prevalence indicators among young people aged 15-24 years in Zambia: An indepth analysis of the 2001-2002 and 2007 Zambia Demographic and 
Health Surveys. SAHARA J. 2013; 10: 149-162.

PubMed: https://www.ncbi.nlm.nih.gov/pmc/articles/PMC4039133/

3. Hallett TB, Aberle-Grasse J, Bello G, Boulos LM, Cayemittes MPA et al. Declines in HIV prevalence can be associated with changing sexual behaviour in Uganda, urban Kenya, Zimbabwe, and urban Haiti. Sex Transm Infect. 2006; 82(Suppl I): i1-i8.

PubMed: https://www.ncbi.nlm.nih.gov/pubmed/16581753

4. Bello G, Simwaka B, Ndhlovu T, Salaniponi F, Hallett TB. Evidence for changes in behaviour leading to reductions in HIV prevalence in urban Malawi. Sex Transm Infect. 2011; 87: 296e - 300e.

PubMed: https://www.ncbi.nlm.nih.gov/pmc/articles/PMC3252594/

5. UNAIDS. UNAIDS report on the global AIDS epidemic 2010. http:// www.unaids.org/globalreport/

6. UNAIDS. GAP report. 2015. http://www.unaids.org/sites/default/files/ media_asset/UNAIDS_Gap_report_en.pdf

7. Mondal MN, Shitan M. Factors affecting the HIVIAIDS epidemic: an ecological analysis of global data. Afr Health Sci. 2013; 13: 301-310 PubMed: https://www.ncbi.nlm.nih.gov/pubmed/24235928

8. World Health Organization. Progress report 2011: Global HIV/AIDS response. Epidemic update and health sector progress towards universal access WHO, UNICEF, UNAIDS. 2011.

http://whqlibdoc.who.int/publications/2011/9789241502986_eng.pdf

9. Alamrew Z, Bedimo M, Azage M. Risky sexual practices and associated factors for HIVIAIDS infection among private college students in Bahir Dar city, northwest Ethiopia. ISRN Public Health. 2013; 1-9.

10. Kimanga DO, Ogola S, Umuro M, Ng'ang'a A, Kimondo L, et al. KAIS Study Group. Prevalence and incidence of HIV infection, trends, and risk factors among persons aged 15-64 years in Kenya: results from a nationally representative study. J Acquir Immune Defic Syndr. 2014; 66 (Suppl 1): S13-26.

11. Reid SD, Malow RM, Rosenberg R. Alcohol, drugs, sexual behavior and HIV in Trinidad and Tobago--the way forward. J Int Assoc Physicians AIDS Care (Chic). 2012; 11: 66-82.

12. Bourne PA, South-Bourne N, Francis CG. Knowledge, attitude and practices of adults of the reproductive years on reproductive health matters, with emphasis on HIV infected people in a Caribbean society. N Am J Med Sci. 2010; 2: 381-388.

13. Barbados National HIV/ AIDS Commission. (2008) National Strategic Plan for HIV 2008-2013: http://nhacbb.org/plugins/p13_download_ manager/getfile.php? categoryid=68\&p13_sectionid=1\&p13 fileid=106\&p13_versionid=106

14. Kumar A, Kilaru KR, Sandiford S. Trends in the HIV related hospital admissions in the HAART era in Barbados, 2004-2006. AIDS Res Ther. 2007; $7: 4$

15. Kumar A, Kilaru KR, Forde S, Roach TC. Changing HIV infectionrelated mortality rate and causes of death among persons with HIV infection before and after the introduction of highly active antiretroviral therapy: analysis of all HIV-related deaths in Barbados, 1997-2005. J Int Assoc Physicians AIDS Care (Chic). 2006; 5: 109-114.

16. Amon J, Brown T, Hogle J, MacNeil J, Magnani R, et al. Behavioral Surveillance Surveys, BSS. Guidelines for repeated behavioral surveys in populations at risk of HIV. Family Health International [FHI], Implementing AIDS Prevention and Care Project [IMPACT]. 2000. 350 https://www.who.int/hiv/strategic/en/bss_fhi2000.pdf

17. National HIVIAIDS Commission of Barbados. National strategic plan for HIV 2014-2018: Investing for results. HIV Gateway. 2014; 1-25 www.hivgateway.com/entry/f20b7b6d6d36207b1f7542dce0903944/
18. Kilaru KR, Kumar A, Sippy N. CD4 cell counts in adults with newly diagnosed HIV infection in Barbados. Rev Panam Salud Publica. 2004 16: 302-307

19. Bombereau G, Allen CF. Social and cultural factors driving the HIV epidemic in the Caribbean: a literature review. HIV Gateway 2008; 1-11 http://www.hivgateway.com/files/b879ac244e4aa7fd3fa8efb405482949/BombereauAllenLitReview.pdf

20. Drakes N, Perks C, Kumar A, Quimby K, Clarke C, et al. Prevalence and risk factors for inter-generational sex: a cross-sectional cluster survey of Barbadian females aged 15-19. BMC Womens Health 2013; 13, 53.

PubMed: https://www.ncbi.nlm.nih.gov/pubmed/24373740

21. Kumar A, Carter R, Kumari G, Doughlin C, Jacob C. Risk behaviors and predisposition for HIV infection among the secondary school students' in Barbados - results from a national survey. West Indian Med J. 2005; 54(suppl 2): 14

22. Kumar A. Report on the Secondary School Behavioral Surveillance Survey 2003/2004. HIV Gateway http://www.hivgateway.com/files/ c67da8fa68390a67578e58ea5f27f175/Report_on_the_Secondary_ School_Behavioural_Surveillance_Survey_2003-2004.pdf

23. Pettifor AE, van der Straten A, Dunbar MS, Shiboski SC, Padian NS Early age of first sex: A risk factor for HIV infection among women in Zimbabwe, AIDS. 2004; 18: 1435-1442.

PubMed: https://www.ncbi.nlm.nih.gov/pubmed/15199320

24. Dixon-Mueller R. Starting young: sexual initiation and HIV prevention in early adolescence. AIDS and Behavior. 2009; 13: 100-109.

PubMed: https://www.ncbi.nlm.nih.gov/pubmed/18389362

25. Hindin MJ, Fatusi AO. Adolescent Sexual and Reproductive Health in Developing Countries: An Overview of Trends and Interventions. Int Perspect Sex Reprod Health. 2009; 35: 58-62

PubMed: https://www.ncbi.nlm.nih.gov/pubmed/19620089

26. Kumar A, Bent V. Characteristics of HIV-infected childbearing women in Barbados. Rev Panam Salud Publica. 2003; 13: 1-9.

27. Kumar A, Waterman I, Kumari G, Carter AO. Prevalence and correlates of serostatus disclosure in HIV-infected adults attending the follow up and treatment clinic in Barbados. AIDS Patient Care STDS. 2006; 20 724-730.

PubMed: https://www.ncbi.nlm.nih.gov/pubmed/17052142

28. Mah TL, Halperin DT. Concurrent sexual partnerships and the HIV epidemics in Africa: evidence to move forward. AIDS Behav. 2010; 14 11-16.

PubMed: https://www.ncbi.nlm.nih.gov/pubmed/18648926

29. Epstein $\mathrm{H}$. The mathematics of concurrent partnerships and HIV: a commentary on Lurie and Rosenthal, 2009. AIDS Behav. 2009; 14: 29-30. PubMed: https://www.ncbi.nlm.nih.gov/pubmed/19866354

30. Kalichman SC, Ntseane D, Nthomang K, Segwabe M, Phorano O. Recent multiple sexual partners and HIV transmission risks among people living with HIVIAIDS in Botswana. Sex Transm Infect. 2007; 83: 371-375

PubMed: https://www.ncbi.nlm.nih.gov/pmc/articles/PMC2659030/

31. Calsyn DA, Cousins SJ, Hatch-Maillette MA, Forcehimes A, Mandler $\mathrm{R}$, et al. Sex Under the Influence of Drugs or Alcohol: Common for Men in Substance Abuse Treatment and Associated with High Risk Sexual Behavior. Am J Addict. 2010; 19: 119-127.

PubMed: https://www.ncbi.nlm.nih.gov/pmc/articles/PMC2861416/

32. Kalichman SC, Cain D, Simbayi LC. Multiple recent sexual partnerships and alcohol use among sexually transmitted infection clinic patients, Cape Town, South Africa. Sex Transm Dis. 2011; 38: 18-23. PubMed: https://www.ncbi.nlm.nih.gov/pubmed/20625349 
33. Scott-Sheldon LA, Carey MP, Vanable PA, Senn TE, Coury-Doniger $\mathrm{P}$, et al. Alcohol consumption, drug use, and condom use among STD clinic patients. J Stud Alcohol Drugs. 2009; 70: 762-770.

PubMed: https://www.ncbi.nlm.nih.gov/pubmed/19737501

34. Abiodun O, Sotunsa J, Ani F, Jaiyesimi E. Knowledge of HIVIAIDS and predictors of uptake of HIV counseling and testing among undergraduate students of a privately owned university in Nigeria. BMC Research Notes. 2014; 7: 639.

PubMed: https://www.ncbi.nlm.nih.gov/pubmed/25217120

35. Mahande MJ, Phimemon RN, Ramadhani HO. Factors associated with changes in uptake of HIV testing among young women (aged 15-24) in Tanzania from 2003 to 2012. Infectious Diseases of Poverty. 2016; 5: 92. PubMed: https://www.ncbi.nlm.nih.gov/pmc/articles/PMC5011841/

36. Peltzer K, Matseke G. Determinants of HIV testing among young people aged 18-24 years in South Africa. Afr Health Sci. 2013; 13: 1012-1020.

PubMed: https://www.ncbi.nlm.nih.gov/pmc/articles/PMC4056506/
37. Marks G, Crepaz N, Janssen RS. Estimating sexual transmission of HIV from persons aware and unaware that they are infected with the virus in the USA. AIDS. 2006; 20: 1447-1450.

PubMed: https://www.ncbi.nlm.nih.gov/pubmed/16791020

38. Tenkorang EY, Owusu GA. Correlates of HIV testing among women in Ghana: some evidence from the Demographic and Health Surveys. AIDS Care. 2010; 22: 296-307.

PubMed: https://www.ncbi.nlm.nih.gov/pubmed/20390509

39. Cawley C, Wringe A, Slaymaker E, Todd J, Michael D, et al. The impact of voluntary counselling and testing services on sexual behaviour change and HIV incidence: observations from a cohort study in rural Tanzania. BMC Infect Dis. 2014; 14: 159.

PubMed: https://www.ncbi.nlm.nih.gov/pubmed/24655360

40. Hall HI, Holtgrave DR, Maulsby C. HIV transmission rates from persons living with HIV who are aware and unaware of their infection. AIDS. 2012; 26: 893-896.

PubMed: https://www.ncbi.nlm.nih.gov/pubmed/22313960 